\title{
Understanding Pedestrian Interactive Behaviors under the Different Level of Services on Stairways
}

\author{
Jianhong Ye, ${ }^{1,2,3}$ Xiaonian Shan $\left(\mathbb{D},{ }^{4}\right.$ Xiaohong Chen, ${ }^{2}$ and Mengxiao $\mathrm{Yu}^{5}$ \\ ${ }^{1}$ School of Transportation Engineering, Tongji University, No. 4800 Cao'an Road, Shanghai, 201804, China \\ ${ }^{2}$ Key Laboratory of Road and Traffic Engineering of the Ministry of Education, Tongji University, No. 4800 Cao'an Road, \\ Shanghai, 201804, China \\ ${ }^{3}$ UN Environment-Tongji Institute of Environment for Sustainable Development, No. 4800 Caoan Road, Shanghai, 201804, China \\ ${ }^{4}$ College of Civil and Transportation Engineering, Hohai University, No. 1 Xikang Road, Nanjing, 210098, China \\ ${ }^{5}$ Nanjing Institute of City \& Transport Planning Company Limited, No. 63 Zhujiang Road, Nanjing, 21002, China \\ Correspondence should be addressed to Xiaonian Shan; shanxiaonian@hhu.edu.cn
}

Received 16 January 2019; Revised 1 April 2019; Accepted 12 June 2019; Published 27 June 2019

Guest Editor: Alessandro Corbetta

Copyright ( 2019 Jianhong Ye et al. This is an open access article distributed under the Creative Commons Attribution License, which permits unrestricted use, distribution, and reproduction in any medium, provided the original work is properly cited.

\begin{abstract}
Stairways serve as important walking facilities for pedestrians, especially in metro stations, but researches of pedestrian traffic on stairways are not sufficient. This paper investigates pedestrian interactive behaviors (PIBs) under the different level of services (LOS) on stairways, including overtaking behavior and evasive behavior on stairways. Macro and micro indicators are proposed and calculated based on field observation collected from two stairway flights in a certain metro station in Shanghai, China. Results of macro indicators reveal that the characteristics of overtaking behavior and evasive behavior have both similarities and differences. As for similarities, neither of these two types of behaviors would occur under extremely low or high densities, representing LOS A or LOS F. Under other ranges of density, occurrence intensities of pedestrian interactive behaviors on stairways are different. Overtaking behavior intensity shows a rapid increase trend with the density from low to medium, while evasive behavior intensity keeps a certain value. Results of micro indictors show that the available space for overtaking behavior and evasive behavior is the main factor contributing to the above similarities and differences. Characteristics of PIBs under the different LOS present in highway capacity manual are discussed based on field observations. Findings of this research are helpful to understand the knowledge of PIBs on stairways for a better stairway traffic design and level of service evaluation.
\end{abstract}

\section{Introduction}

Pedestrian stairway is one of the most common and important walking facilities. It is widely used in transportation buildings (such as metro stations) and other pedestrian traffic areas. Pedestrian interactive behaviors (PIBs), including overtaking behavior and evasive behavior, always occur when pedestrians move in cluster on stairways, which have significant impacts on the comfort and safety of pedestrian traffic on stairways. Thus, it is important to understand the characteristics of PIBs under the different level of service (LOS) on stairways.

Previous studies mainly focused on pedestrian walking features and the analysis of factors affecting walking speed on stairways [1-6]. For example, Templer [1] found that pedestrians have preference to walk right-hand side on stairs. Yi et al. [2] conducted an experimental study about walking characteristics on U-shaped stairways. They pointed out that pedestrians concentrated in the middle part of the stair when the facility was narrow but had preference to walk along the stair edge when it became wider. Yang [3] analyzed the behavior characteristics of young students when they were walking on stairs. Phenomena of queuing on platforms, confluences at entrances, and subgroup behavior have been observed. And results showed that pedestrians have higher possibility of overtaking in emergency conditions. Fujiyama and Tyler $[4,5]$ analyzed the factors that can affect walking speed and established a model to estimate pedestrian walking 


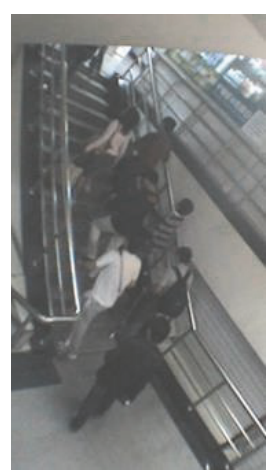

(a) Ascending flow on stairway A

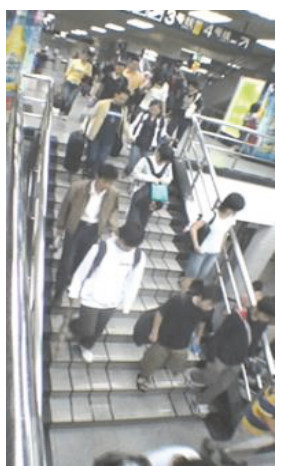

(b) Descending flow on stairway B

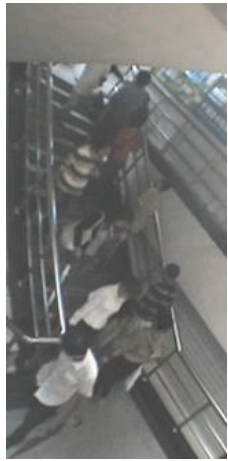

(c) Bidirectional flow on stairway A

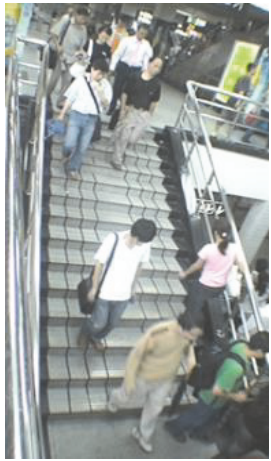

(d) Bidirectional flow on stairway B

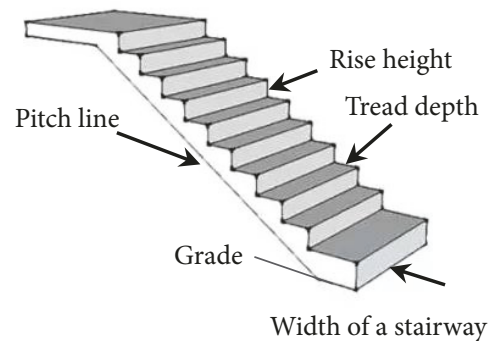

(e) Physical parameters of a stairway

FIgURE 1: Two stairways observed with different flow patterns.

speed on stairways. Results revealed that the speed of pedestrians became slower when they are surrounded by the other persons.

As for the analysis of PIBs, many researchers have conducted studies on level walkways [7-14]; studies about PIBs on stairways were relatively inadequate. Pauls [15] pointed that the lateral oscillation of pedestrians walking on stairways would increase when their speed become slower. Fujiyama and Tyler [16] observed the avoidance behavior of pedestrians on bidirectional stairways. Furthermore, in Highway Capacity Manual (HCM) 2010, the LOS criteria for stairway traffic are developed based on the analysis of probability of conflict among pedestrians when PIBs occur at different density levels [17]. However, it should be admitted that quantitative studies on pedestrian behavior on stairways are still insufficient, and the descriptions of these behavior characteristics at different LOS presented in HCM 2010 are quite vague. For example, at LOS B, it states the following: "Occasional need to adjust path to avoid conflicts" and "Frequent need to adjust path to avoid conflicts" for LOS C. However, how to quantify the degree of such needs and give more explicit description for stairway traffic status at different LOS is not fully supported by current available knowledge.

From previous studies, we can find that quantitative studies on PIBs on stairways are quite scarce. There is a gap between the research on individual walking behavior features and the traditional research on pedestrian flow characteristics. These lead to no comprehensive understanding of stairway traffic. Therefore, the main objective of this paper is to strengthen the knowledge of PIB characteristics on stairways and to provide a theoretical support for the planning and design of stairway facilities as well as the evaluation of stairway traffic flow.

This paper aims to extend the understanding of PIBs on stairways to quantitatively investigate the stairway pedestrian flow characteristics, including overtaking behavior and evasive behavior. On one hand, macro indicators describing the frequency of events of PIBs events are analyzed with the variation of pedestrian traffic density. On the other hand, micro indicators describing the characteristics of PIBs are developed to reveal how pedestrians interacted with each other. Connections between macro and micro indicators are also built up to give a full picture of pedestrian traffic flow phenomena and rules on stairways. The description of PIBs under the different LOS on stairways is discussed according to HCM 2010. The paper is organized as follows. Data collection is introduced firstly in Section 2. Section 3 analyzes the characteristics of overtaking behavior on unidirectional stairways. And evasive behavior on bidirectional stairways is presented in Section 4. Descriptions of PIBs under the different LOS on stairways are discussed in Section 5. This paper ends with a brief conclusion and discussion on future studies in Section 6.

\section{Data}

2.1. Observation Sites. To analyze the characteristics of PIBs on stairways, the observation sites should be isolated from other transportation modes. And the sites could be bidirectional to observe pedestrian evasive behavior. Meanwhile, pedestrian traffic is expected to vary with density range to cover pedestrian flow of low, middle, and high densities. According to filed observation, Zhong-Shan Park Station is selected as the observation site, which is a metro station in Shanghai with large amounts of pedestrian flow and three metro lines interchanging. In 2016, daily passenger flow volumes including transfer volumes in this station were 570,000 ride trips. During peak hours, passenger flow volumes make up nearly 20 percent of the total daily volumes. Thus, the various pedestrian flow densities could be observed in this site.

As can be seen in Figure 1, two flights of stairways in the metro station are selected for field observation. Physical characteristics of the observed stairways are given in Table 1, illustrated in Figure 1(e). Bidirectional flow is allowed in these two stairways all the time in a day. Stairway A serves ascending pedestrian flow (see Figure 1(a)), and Stairway B serves descending flow (see Figure 1(b)). For peak hours, bidirectional pedestrian flows are observed on such two stairways (see Figures 1(c) and 1(d)). The average grades of these two stairways are about $25^{\circ}$, and the tread width and riser height are $0.30 \mathrm{~m}$ and $0.15 \mathrm{~m}$, respectively. 
TABLE 1: Physical parameters of the two observed stairways.

\begin{tabular}{lccccc}
\hline Facility & Width $(\mathrm{m})$ & Pitch line $(\mathrm{m})$ & Grade $\left(^{\circ}\right)$ & Tread Width $(\mathrm{m})$ & Step Riser Height $(\mathrm{m})$ \\
\hline Stairway A & 1.77 & 4.82 & 25.8 & 0.30 & 0.15 \\
Stairway B & 2.10 & 4.71 & 24.4 & 0.30 & 0.15 \\
\hline
\end{tabular}

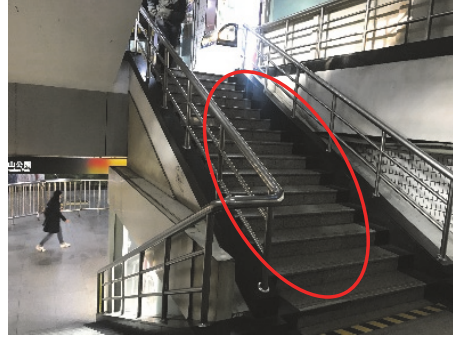

(a) The observed ascending stairway

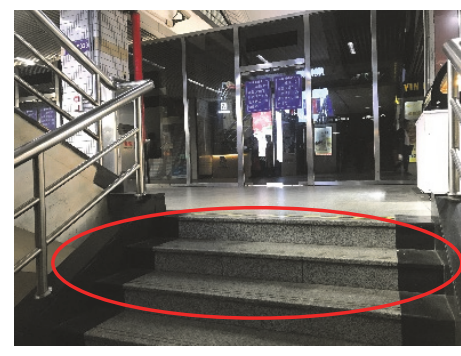

(b) A landing area upstream of the observed stairway

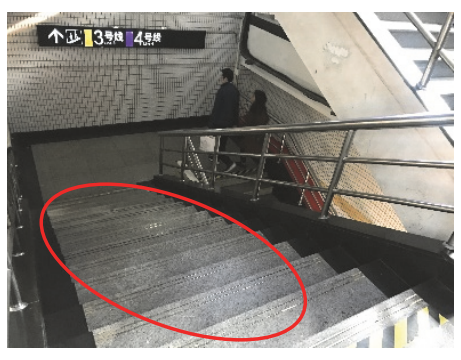

(c) A landing area downstream of the observed stairway

FIGURE 2: Details of connected landings of the observed ascending stairway.

With consideration of the impact of connection with other spaces on PIBs, Figure 2 shows the details of the connected landings and other flights of the observed ascending stairway. There are four flights for the ascending stairway. The second flight is selected as the observed object; see Figure 2(a). There is a landing area to connect with the third flight upstream of the second flight; see Figure 2(b). There is also a landing area to connect with the first flight downstream of the second flight; see Figure 2(c). Similarly, as for the descending stairway, the top flight is selected as the field observation; see Figure 3(a). There is a station hall upstream of the observed stairway; see Figure 3(b). And there is a landing area to connect with another flight; see Figure 3(c). Furthermore, the outlined ellipses are set with the red lines to associate with the location of the observed flight.

Field observation is conducted by recording the videos of pedestrian traffic on the two stairways during peak commuting hours, which are 7:00 10:00 in the morning and 16:00 19:00 in the evening. The reason for selecting peak hours as observation time is twofold. One is to obtain more highdensity traffic flow data, and the other is to facilitate observing interactive behavior of pedestrians, since pedestrians usually walk in a hurry during peak hours, which will cause high possibility of pedestrian overtaking behavior and evasive behavior.

2.2. Indicator Definition. Two different categories of indicators are introduced for describing the characteristics of PIBs. A person who needs to overtake the slow pedestrians in unidirectional pedestrian flow on stairways represents overtaking behavior; and a person who needs to avoid the opposite pedestrians in bidirectional pedestrian flow on stairways represents evasive behavior. Shan et al. defined these two types of indictors on the walkway characteristics of PIBs, named macro and micro indicators [11]. Similarly, the macro indicators, representing the occurrence frequencies of PIBs, and micro indicators, representing the space necessary for taking PIBs for this research, are listed in Table 2.

A brief description of the meaning of these indicators is given as follows:

(i) The occurrence intensity of PIBs $\left(\rho_{\mathrm{o}}, \rho_{\mathrm{e}}\right)$. They are defined as the number of PIB events occurring per unit time at a certain density level. They are the balanced outcome of PIB demand and available space supply, which can represent the possibilities of PIBs occurrence at different pedestrian flow densities.

(ii) The proportion of sideways $\left(R_{\mathrm{o}}, R_{\mathrm{e}}\right)$. They are defined as the proportion of sideways PIB events to the total PIB events at a certain density to illustrate the difficulty of taking behaviors.

(iii) The initial longitudinal distances of interactive behaviors $\left(\mathrm{L}_{\mathrm{o}}, \mathrm{L}_{\mathrm{e}}\right)$. These indicators are defined as the longitudinal distances between the two pedestrians when the PIB event starts; see Figure 4. Such indicators reflect the pedestrians' available longitudinal space during the interactive behavior process.

(iv) The final lateral distances of interactive behaviors $\left(\mathrm{H}_{\mathrm{o}}, \mathrm{H}_{\mathrm{e}}\right)$. They are defined as the lateral distances between the two pedestrians at the moment when the interactive behavior events are over. The indicators reflect the pedestrians' available lateral space during the interactive behavior process.

2.3. Indicator Calculation. As for data extraction, a manual counting method is adopted with the help of a video player software, which can play (including playing frame by frame, a frame equals 0.04 seconds) and replay the recorded videos. 


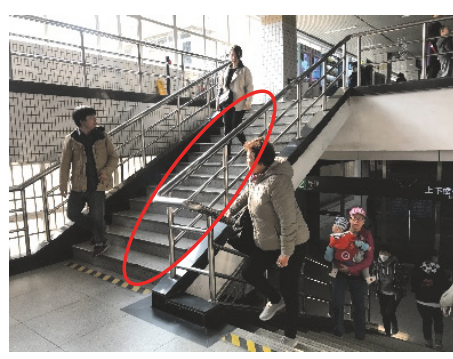

(a) The observed descending stairway

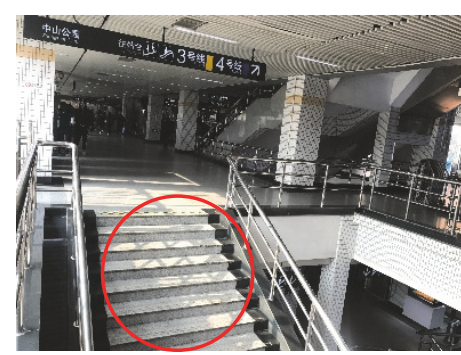

(b) A station hall upstream of the observed stairway

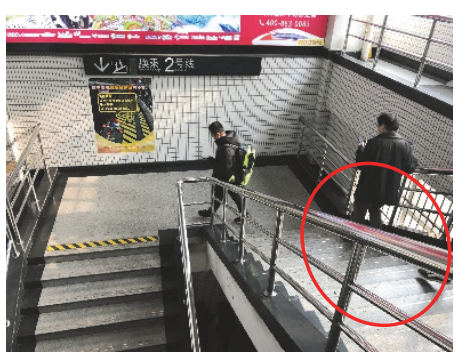

(c) A landing area downstream of the observed stairway

FIGURE 3: Details of connected landings of the observed descending stairway.

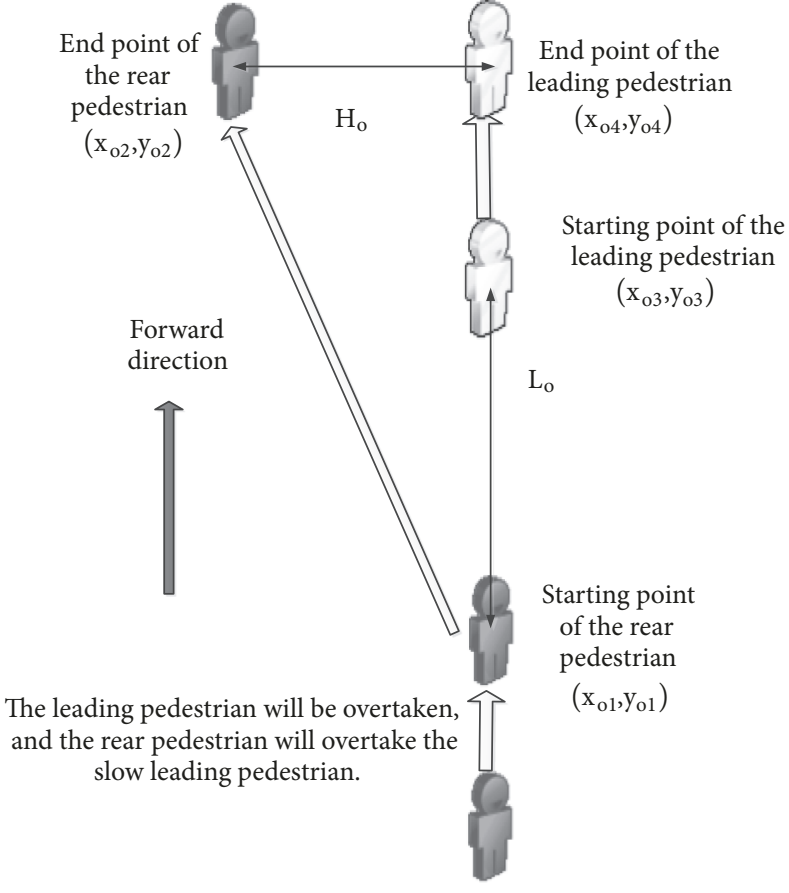

(a) Pedestrian overtaking behavior

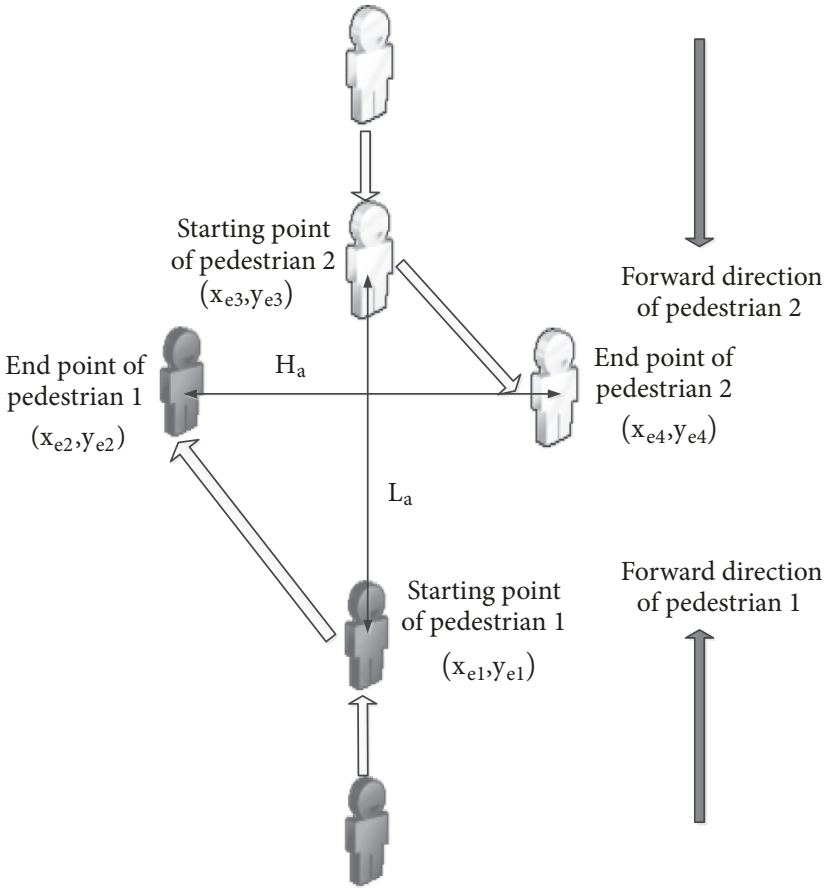

(b) Pedestrian evasive behavior

FIgURE 4: Schematic drawing of PIBs.

TABLE 2: Macro and micro indicators of PIB characteristics.

\begin{tabular}{lcc}
\hline Behavior Type & Macro Indicators & Micro Indicators \\
\hline Overtaking behavior & Occurrence intensity $\left(\rho_{\mathrm{o}}\right)$ & The initial longitudinal distance of overtaking behavior $\left(\mathrm{L}_{\mathrm{o}}\right)$ \\
& Proportion of sideways $\left(R_{\mathrm{o}}\right)$ & The final lateral distance of overtaking behavior $\left(\mathrm{H}_{\mathrm{o}}\right)$ \\
Evasive behavior & Occurrence intensity $\left(\rho_{\mathrm{e}}\right)$ & The initial longitudinal distance of evasive behavior $\left(\mathrm{L}_{\mathrm{e}}\right)$ \\
& Proportion of sideways $\left(R_{\mathrm{e}}\right)$ & The final lateral distance of evasive behavior $\left(\mathrm{H}_{\mathrm{e}}\right)$ \\
\hline
\end{tabular}

For macro indicators of PIB occurrence intensities, each overtaking behavior or evasive behavior can be recorded, as well as the density, when PIBs are happening. Thus, we can calculate the total number of PIBs events (with the symbol of $\mathrm{N}_{\mathrm{oi}}$ and $\mathrm{N}_{\mathrm{ei}}$, resp.) that happened at a certain density. We divided the observed time period into more than 4000 portions with the unit of $5 \mathrm{~s}$ for each portion. And density of each portion is also recorded to sum the total time length $\left(\mathrm{T}_{\mathrm{i}}\right)$ for a certain density $\mathrm{i}$. The occurrence intensities $\left(\rho_{\mathrm{o}}, \rho_{\mathrm{e}}\right)$ can be calculated using the following formulas:

$$
\begin{aligned}
& \rho_{\mathrm{oi}}=\frac{\mathrm{N}_{\mathrm{oi}}}{\mathrm{T}_{\mathrm{i}}} \\
& \rho_{\mathrm{ei}}=\frac{\mathrm{N}_{\mathrm{ei}}}{\mathrm{T}_{\mathrm{i}}}
\end{aligned}
$$




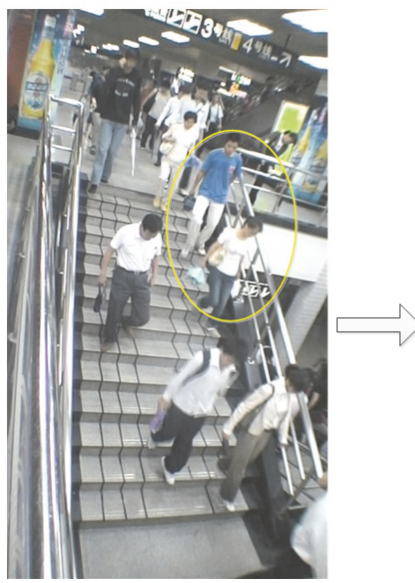

(a) Starting point of overtaking behavior

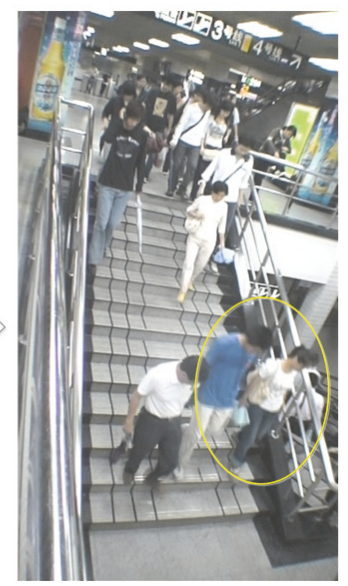

(b) Ending point of overtaking behavior

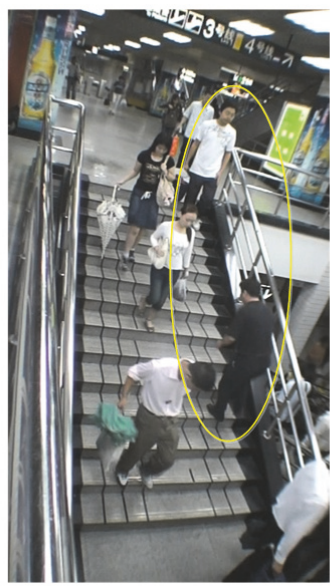

(c) Starting point of evasive behavior

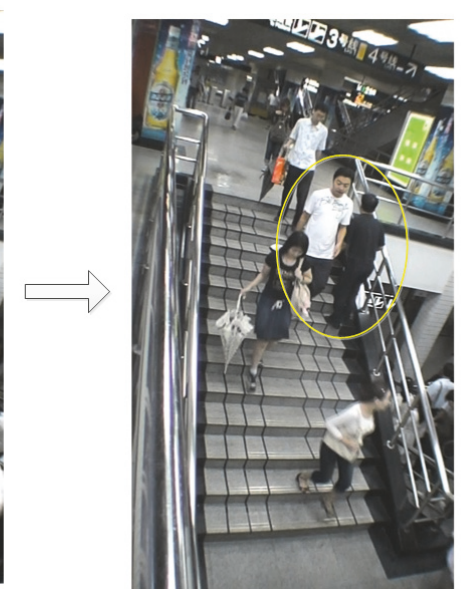

(d) Ending point of evasive behavior

FIGURE 5: Illustration of the starting point and ending point of PIBs.

Meanwhile, at the ending point of PIBs, we can determine whether the behavior is a sideways behavior or not; thus the total of sideways behavior at a certain density could be summed $\left(\mathrm{S}_{\mathrm{oi}}, \mathrm{S}_{\mathrm{ei}}\right)$. And the proportions of sideways behavior to the total events at a certain density could be calculated with the following formulas:

$$
\begin{aligned}
& R_{\mathrm{oi}}=\frac{\mathrm{S}_{\mathrm{oi}}}{\mathrm{N}_{\mathrm{oi}}} \\
& R_{\mathrm{ei}}=\frac{\mathrm{S}_{\mathrm{ei}}}{\mathrm{N}_{\mathrm{ei}}}
\end{aligned}
$$

It should be noted that theoretically the density is the instant number of pedestrians on stairways divided by the observed area. But, in practice, the statistical interval for density calculation is 5 seconds because it could be regarded that the average density will mostly remain the same in five seconds [11].

For micro distance indicators, the horizontal and vertical coordinates of the key points are recorded with the consideration of the feet positions of pedestrians and physical characteristics of stairways. The key points of PIBs include the starting point and end point, as can be seen in Figure 3. The starting points of PIBs are defined as the positions where the pedestrians start to change their walking directions; see Figures 5(a) and 5(c). The ending points of PIBs are defined as the positions where two pedestrians are paralleled to the lateral; see Figures 5(b) and 5(d). The tread width and the equidistant tapes pasted on stairways can be helpful to estimate such distances. Then the micro indicators can be computed using the following formulas:

$$
\begin{aligned}
\mathrm{L}_{\mathrm{o}} & =\left|\mathrm{y}_{\mathrm{o} 3}-\mathrm{y}_{\mathrm{o} 1}\right| \\
\mathrm{H}_{\mathrm{o}} & =\left|\mathrm{x}_{\mathrm{o} 4}-\mathrm{x}_{\mathrm{o} 2}\right| \\
\mathrm{L}_{\mathrm{e}} & =\left|\mathrm{y}_{\mathrm{e} 3}-\mathrm{y}_{\mathrm{e} 1}\right| \\
\mathrm{H}_{\mathrm{e}} & =\left|\mathrm{x}_{\mathrm{e} 4}-\mathrm{x}_{\mathrm{e} 2}\right|
\end{aligned}
$$

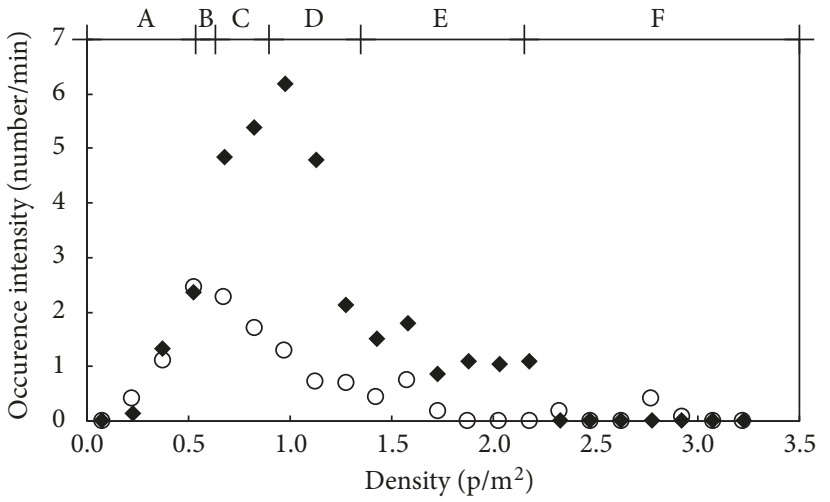

- On ascending stairway

- On descending stairway

FIGURE 6: Macro characteristics of pedestrian overtaking behavior on stairways.

\section{Pedestrian Overtaking Behavior On Stairways}

3.1. Occurrence Intensities on Ascending and Descending Stairways. During the time period of field observation, a total number of 120 pedestrian overtaking behavior events on ascending stairway are observed, with the density ranging from 0.15 to $2.7 \mathrm{p} / \mathrm{m}^{2}$. Similarly, 63 pedestrian overtaking behavior events are collected on descending stairway, with the density ranging from 0.15 to $3.0 \mathrm{p} / \mathrm{m}^{2}$. Through classifying available density values into sequential subgroups with the unit of $0.15 \mathrm{p} / \mathrm{m}^{2}$ interval to aggregate behavior samples in the same density group, the distribution characteristics of occurrence intensity of pedestrian overtaking behavior on stairways under varying densities are captured with the different pedestrian flow LOS presented in HCM 2010, as shown in Figure 6. Overall, with the continuous increase of pedestrian flow density, both of the occurrence intensities of 


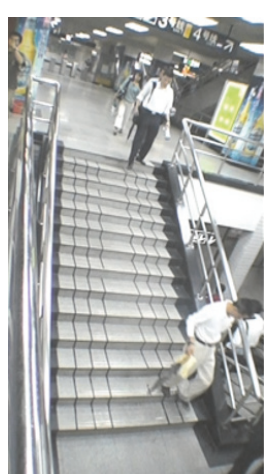

(a) Extremely low density

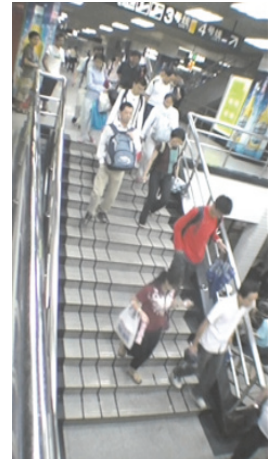

(b) Less than a critical value

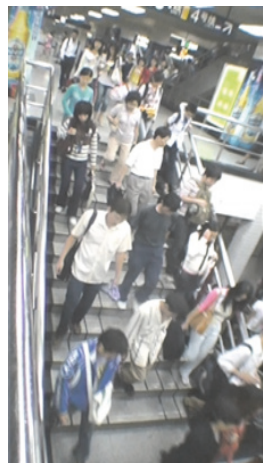

(c) Larger than the critical value

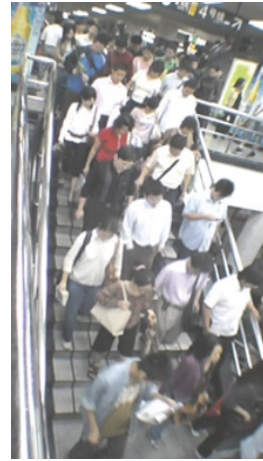

(d) High density

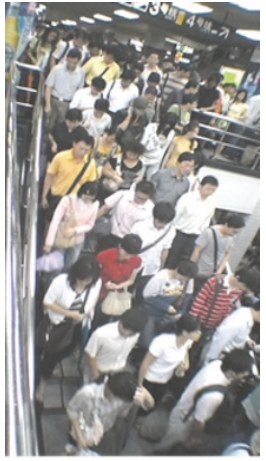

(e) Extremely high density

FIGURE 7: Illustrations of unidirectional stairway traffic at different density levels.

pedestrian overtaking behavior on ascending stairway and on descending stairway first increase and then show a decreasing trend.

As can be seen in Figure 6, at extremely low density with the density less than $0.15 \mathrm{p} / \mathrm{m}^{2}$ or extremely high density with the density greater than $2.4 \mathrm{p} / \mathrm{m}^{2}$ on ascending stairway and greater than $3.0 \mathrm{p} / \mathrm{m}^{2}$ on descending stairway, there is no pedestrian overtaking behavior. This is because, at extremely low density, there is no interaction among pedestrians; thus there is no need to take overtaking behavior; see Figure 7(a). On the contrary, at extremely high density, all pedestrian movements are severely restricted, resulting in no available space for overtaking behavior; see Figure 7(e).

When pedestrian density increases from a low value to a critical value, the occurrence intensity raises dramatically up to the peak value. The density range is about $0.15 \sim 0.9 \mathrm{p} / \mathrm{m}^{2}$ on ascending stairway, and the density range is from 0.15 to $0.6 \mathrm{p} / \mathrm{m}^{2}$ on descending stairway, as shown in Figure 6. This may be interpreted as follows: interaction among pedestrians accrues with density increasing, leading to the demand for overtaking behavior growing up quickly. On the other hand, the space supply on stairways is still enough for pedestrians to overtake other pedestrians; see Figure 7(b). Fast growing overtaking demand and abundant space supply lead the occurrence intensity of overtaking to increase rapidly.

With the continuous increase of pedestrian flow density, larger than the critical value, the occurrence intensity shows a decreasing trend. And the range of density is from 0.9 to $1.65 \mathrm{p} / \mathrm{m}^{2}$ on ascending stairway, with the range from 0.6 to $1.35 \mathrm{p} / \mathrm{m}^{2}$ on descending stairway. The reason for this feature is that although the demand for overtaking still grows up, the space supply on stairways decreases rapidly, which restricts the occurrence of pedestrian overtaking behavior; see Figure 7(c).

As the density increases further, the intensity of pedestrian overtaking behavior keeps a declining tendency with a relatively low rate. The density range on ascending stairway is about $1.65 \sim 2.4 \mathrm{p} / \mathrm{m}^{2}$, and the range of density is from

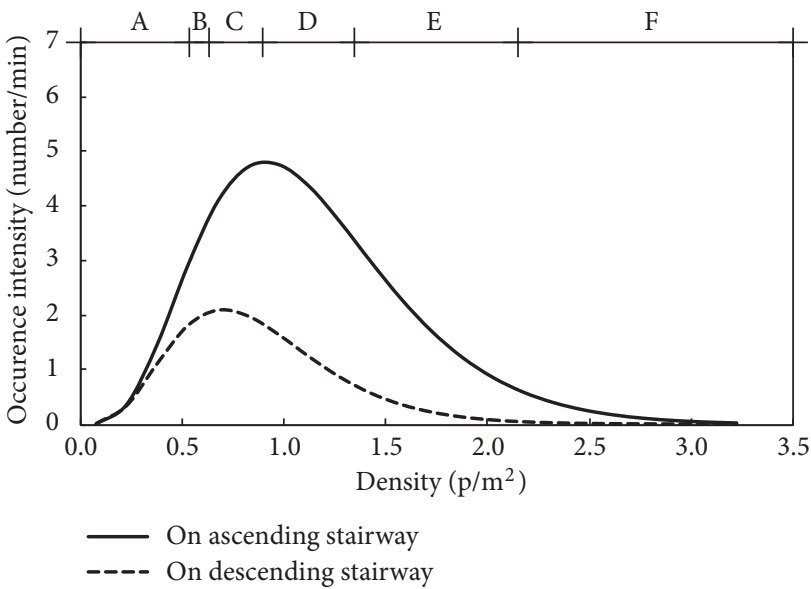

FIGURE 8: Fitting curves between occurrence intensity and pedestrian flow density.

1.35 to $3.0 \mathrm{p} / \mathrm{m}^{2}$ on descending stairway. The continuing decrease of the occurrence intensity shows much intensive constraints of overtaking ability with the little available space for pedestrians; see Figure 7(d).

Furthermore, from the aspect of pedestrian flow LOS, the largest intensity of pedestrian overtaking behavior on ascending stairway is the LOS D, while the largest intensity on descending stairway is the LOS B. There are no pedestrian overtaking events on LOS F. And both the intensities on ascending stairway and descending stairway show very low values on LOS E. Meanwhile, the intensity on ascending stairway at a certain density is always larger than the intensity on descending stairway. The reason may be that pedestrians should focus their mind when they walk on descending stairway.

To fit the functions between pedestrian flow density and occurrence intensity, SPSS software is used with the module of nonlinear regression. Results are shown in Figure 8. The regression functions are as follows: 
TABLE 3: Description of distance indicators on ascending and descending stairways.

\begin{tabular}{lcccc}
\hline \multirow{2}{*}{ Descriptive indexes } & \multicolumn{2}{c}{ On ascending stairway } & \multicolumn{2}{c}{ On descending stairway } \\
& $\mathrm{L}_{\mathrm{oa}}$ & $\mathrm{H}_{\mathrm{oa}}$ & $\mathrm{L}_{\mathrm{od}}$ & 54 \\
$\mathrm{H}_{\mathrm{od}}$ \\
\hline Sample size & 98 & 98 & 25 & 54 \\
Min $(\mathrm{cm})$ & 30 & 30 & 88.3 & 30 \\
Mean $(\mathrm{cm})$ & 91.3 & 74.3 & 185 & 62.3 \\
Max $(\mathrm{cm})$ & 205 & 135 & 1.05 & 115 \\
Key density $\left(\mathrm{p} / \mathrm{m}^{2}\right)$ & 1.05 & 0.9 & 73.5 & 0.75 \\
Average value $(\mathrm{cm})$ & 81.1 & 62.7 & $0.22-2.12$ & $0.22-2.12$ \\
Range of density $\left(\mathrm{p} / \mathrm{m}^{2}\right)$ & $0.26-2.21$ & $0.26-2.21$ & & \\
\hline
\end{tabular}

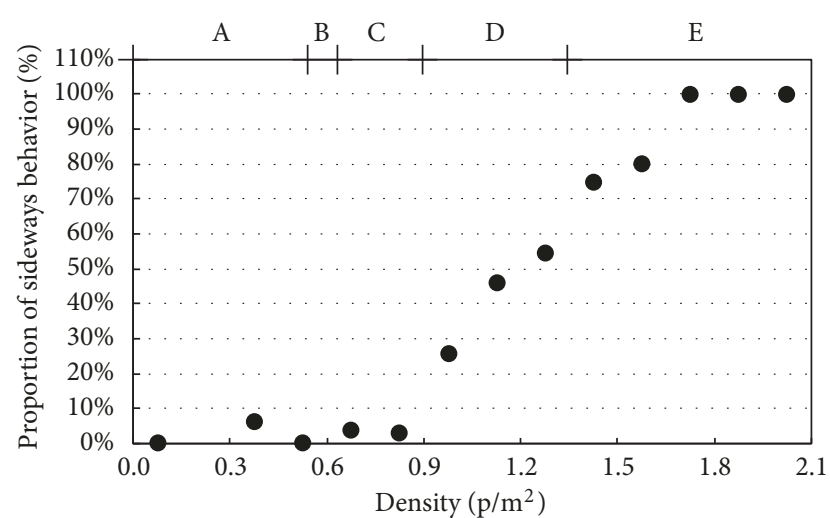

FIgURE 9: Proportion of sideways pedestrian overtaking behavior with the increase of density.

For ascending stairway,

$$
\begin{gathered}
\rho_{\text {oa }}=386.89 \times \mathrm{D}^{4} \times \mathrm{e}^{-4.408 \times \mathrm{D}}, \\
\mathrm{R}^{2}=0.877 ;
\end{gathered}
$$

For descending stairway,

$$
\begin{gathered}
\rho_{\text {od }}=477.71 \times \mathrm{D}^{4} \times \mathrm{e}^{-5.723 \times \mathrm{D},} \\
\mathrm{R}^{2}=0.912,
\end{gathered}
$$

where $\mathrm{D}$ means the pedestrian flow density, $\rho_{\text {oa }}$ is the occurrence intensity on the ascending stairway, and $\rho_{\text {od }}$ is the occurrence intensity on the descending stairway. Both of the values of R-square are larger than 0.85 , showing a good regression.

\subsection{Proportion of Sideways Pedestrian Overtaking Behavior.} As can be seen in Figures 6 and 8, for a certain occurrence intensity, two density values could be obtained. For example, when the occurrence intensity is about 1.4 times/min on ascending stairway, the density may be $0.37 \mathrm{p} / \mathrm{m}^{2}$ or 1.81 $\mathrm{p} / \mathrm{m}^{2}$ based on the fitted function. However, the difficulty of implementing overtaking behavior at such densities is different, which can be illustrated based on the indicator of proportion of sideways behavior, as shown in Figure 9.

As can be seen in Figure 9, with the increase of density, proportion of sideways behavior shows an increasing trend.
When the density is less than $0.9 \mathrm{p} / \mathrm{m}^{2}$, the proportion is less than $10 \%$, at LOS of A, B, and C. Based on field observation, when the density is larger than $1.6 \mathrm{p} / \mathrm{m}^{2}$, all the pedestrian overtaking behavior events are sideways behaviors with the LOS of E. When the density is from $0.9 \mathrm{p} / \mathrm{m}^{2}$ to $1.6 \mathrm{p} / \mathrm{m}^{2}$, the proportion of sideways behavior shows a linear increasing trend from $4 \%$ to $100 \%$, with the LOS of D.

3.3. Microscopic Characteristics of Distance Indicators. For the purpose of deeply understanding the macroscopic characteristics of pedestrian overtaking behavior, most of the behavior events are selected for micro indicators analysis with the 98 samples on ascending stairway and 54 samples on descending stairway. The distance indicators include the initial longitudinal distance $\left(\mathrm{L}_{\mathrm{o}}\right)$ and the final lateral distance $\left(\mathrm{H}_{\mathrm{o}}\right)$. Table 3 shows the descriptive results of such distance indicators on ascending and descending stairways. And the scatter diagrams between such indicators and density are shown in Figure 10.

The method of one by one to calculate the correlations between these two distance indicators and density has been adopted to identify the key densities [11]. As for the ascending stairway, when the density is less than the key density (1.05 $\mathrm{p} / \mathrm{m}^{2}$ ), the longitudinal distance shows a decreasing trend; see Figure 10(a). When the density is larger than $1.05 \mathrm{p} / \mathrm{m}^{2}$, there is no significant relationship between longitudinal distance and density, with the average value of $81.1 \mathrm{~cm}$. For the horizontal distance, in contrast, when the density is less than $0.9 \mathrm{p} / \mathrm{m}^{2}$, we find that there is no significant relationship between horizontal distance and density, with the average value of $62.7 \mathrm{~cm}$; see Figure 10(b). After that, the horizontal distance decreases with the increase of density.

Similarly, the key density of longitudinal distance on descending stairway is also $1.05 \mathrm{p} / \mathrm{m}^{2}$ (see Figure $10(\mathrm{c})$ ), while the density of horizontal distance is $0.75 \mathrm{p} / \mathrm{m}^{2}$ (see Figure $10(\mathrm{~d})$ ). The average values on descending stairway are $73.5 \mathrm{~cm}$ and $57.2 \mathrm{~cm}$.

Thus, the occurrence of overtaking behavior is more dependent on the longitudinal distance rather than horizontal distance. Within a low-density range, the horizontal distance remains almost constant with the increasing density, meaning that available space for pedestrians to overtake is not deducted notably even though the longitudinal distance keeps decreasing. Meanwhile, the space for implementing overtaking behavior is about $75 \mathrm{~cm}$ for longitudinal distance 


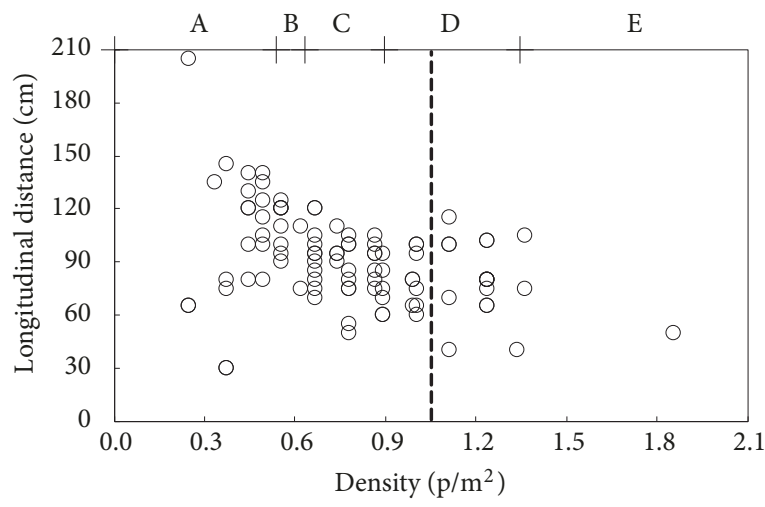

(a) Longitudinal distance on ascending stairway

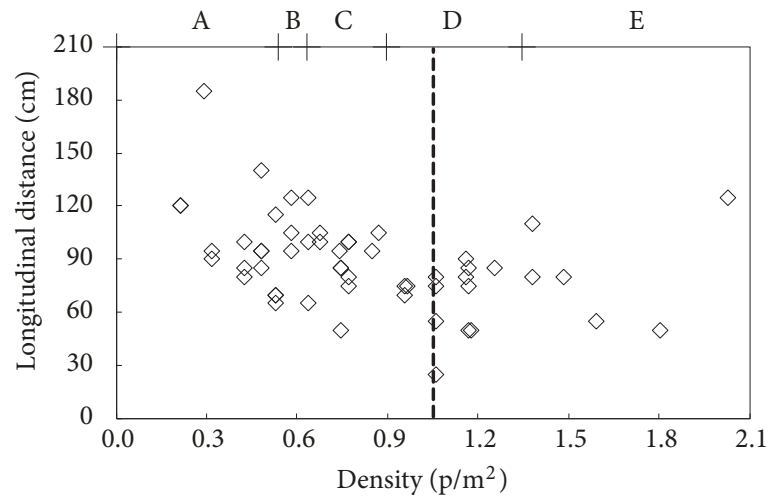

(c) Longitudinal distance on descending stairway

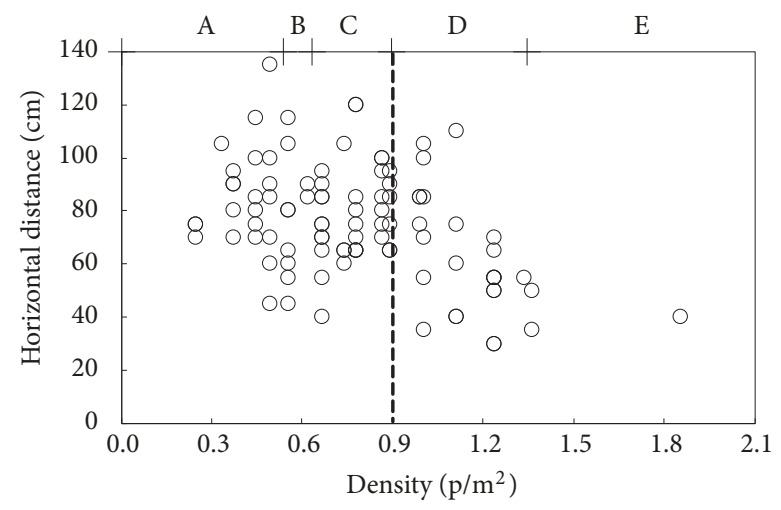

(b) Horizontal distance on ascending stairway

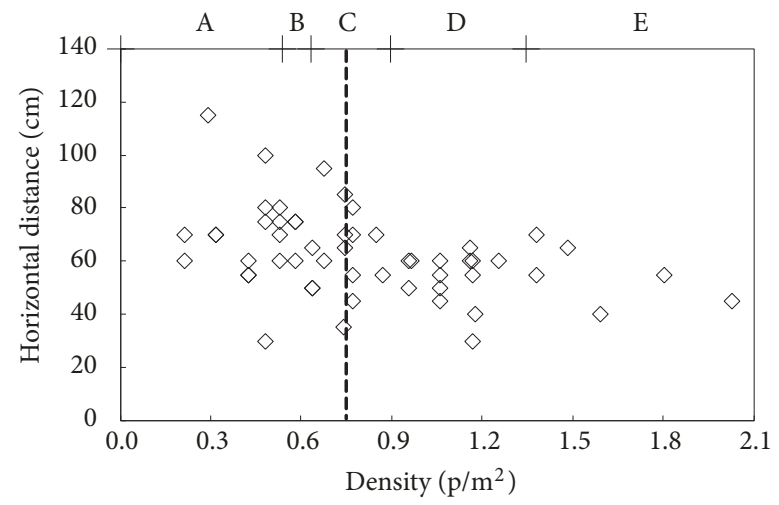

(d) Horizontal distance on descending stairway

FIgURE 10: Microscopic distance indicators of pedestrian overtaking behavior.

and $60 \mathrm{~cm}$ for horizontal distance, which also reflects the space demand for a person walking on stairways. The reason for the differences of micro distances between these two different stairways may be that descending people have already changed their lateral positions before they got the first stair due to the top flight selected as the field observation [18].

The above rules of space supply change for pedestrian overtaking behavior are in line with and support the characteristics of occurrence intensity change with pedestrian flow density. At low-density range, the increasing density leads to much interaction among pedestrians and the overtaking demand rises up. At the same time, the available space for taking behaviors is maintained at a high level. Therefore, the occurrence intensity increases rapidly. As the density goes up further, the interference among pedestrians is intensified and the overtaking demand increases continuously, but unfortunately the available space for overtaking declines sharply (mainly because the micro distances decrease quickly, see Figure 10). Therefore, the occurrence intensity decreases rapidly. Finally, there is no available space at extremely high density, resulting in none of pedestrian overtaking behavior events.

\section{Pedestrian Evasive Behavior on Stairways}

4.1. Occurrence Intensity on Bidirectional Stairways. A total number of 122 samples of pedestrian evasive behavior events

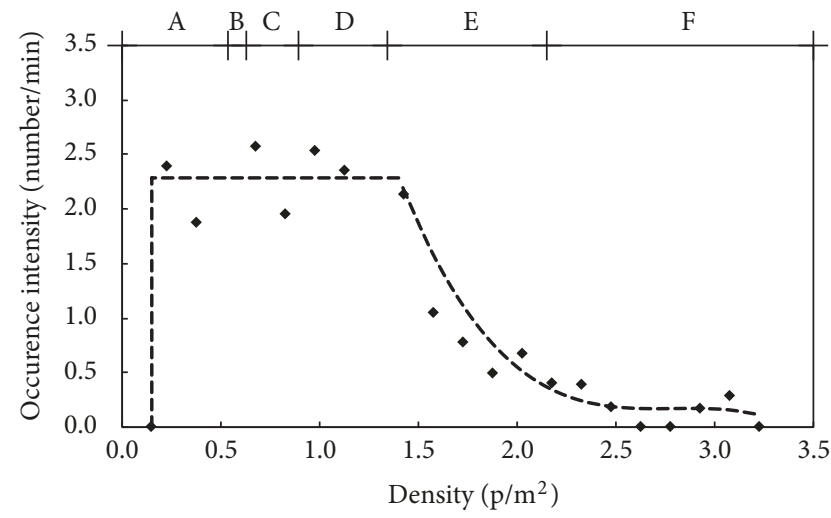

FIGURE 11: Occurrence intensity distribution of pedestrian evasive behavior.

on bidirectional stairways are collected, with the density ranging from 0 to $3.45 \mathrm{p} / \mathrm{m}^{2}$. The available density values are also classified into subgroups with $0.15 \mathrm{p} / \mathrm{m}^{2}$ interval to aggregate behavior samples in the same density group. The distribution characteristics of occurrence intensity of evasive behavior under different LOS defined in HCM 2010 are shown in Figure 11.

As can be seen in Figure 9, at extremely low density (less than $0.15 \mathrm{p} / \mathrm{m}^{2}$ ) or extremely high density (greater than 


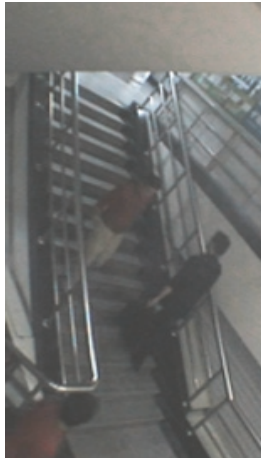

(a) Extremely low density

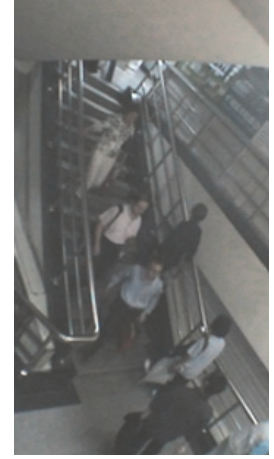

(b) Less than a critical value

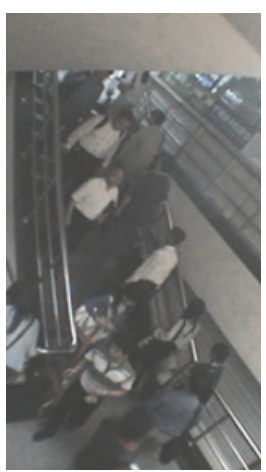

(c) Larger than the critical value

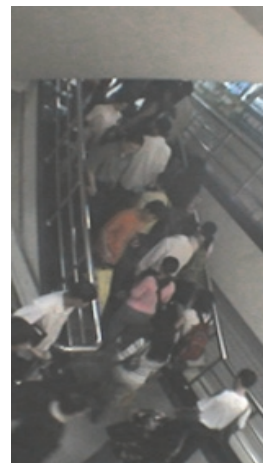

(d) High density

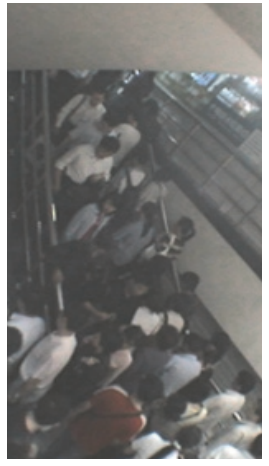

(e) Extremely high density

FIGURE 12: Illustrations of bidirectional stairway pedestrian flow at different density levels.

$3.15 \mathrm{p} / \mathrm{m}^{2}$ ), there are no pedestrian evasive behavior events. The reason is that pedestrians are not influenced by others at extremely low-density level and there is no need to take behavior; see Figure 12(a). On the contrary, at extremely high density, all pedestrian movements are severely restricted; see Figure 12(e). There is no available space for taking evasive behaviors.

As the density increases, pedestrian evasive behavior can be observed and the occurrence intensity remains relatively stable, with the average value of 2.28 times $/ \mathrm{min}$. The range of density is from $0.15 \mathrm{p} / \mathrm{m}^{2}$ to $1.4 \mathrm{p} / \mathrm{m}^{2}$. The reason is that, with the increase of density, the interaction among pedestrians accrues and the demand for taking evasive behaviors grows up quickly. Meanwhile, the space supply for pedestrians to avoid others decreases simultaneously from more pedestrians crowding; see Figure 12(b).

As the density increased over the critical value $\left(1.4 \mathrm{p} / \mathrm{m}^{2}\right)$, the occurrence intensity declined sharply. The reason is that the space supply for pedestrians to avoid others on bidirectional stairway decreases rapidly, which restricts the occurrence of pedestrian evasive behavior events in spite of the increasing demand of taking evasive behaviors; see Figure 12(c).

As the density increases further larger than $1.8 \mathrm{p} / \mathrm{m}^{2}$, the intensity of avoidance behavior keeps the declining tendency but with a relatively lower rate. The continuing decrease of the occurrence intensity is mainly the result of more intensive constraints among pedestrians, which severely restricted the occurrence possibility of pedestrian evasive behavior; see Figure 12(d).

Furthermore, from the aspect of pedestrian flow LOS, the occurrence intensity shows a stable trend when the LOS is $\mathrm{B}, \mathrm{C}$, and D. At LOS E, the intensity shows a decreasing trend. In LOS $\mathrm{F}$, there are few pedestrian evasive behavior events.

The fitted function for the occurrence intensity when the density is larger than $1.4 \mathrm{p} / \mathrm{m}^{2}$ is as follows:

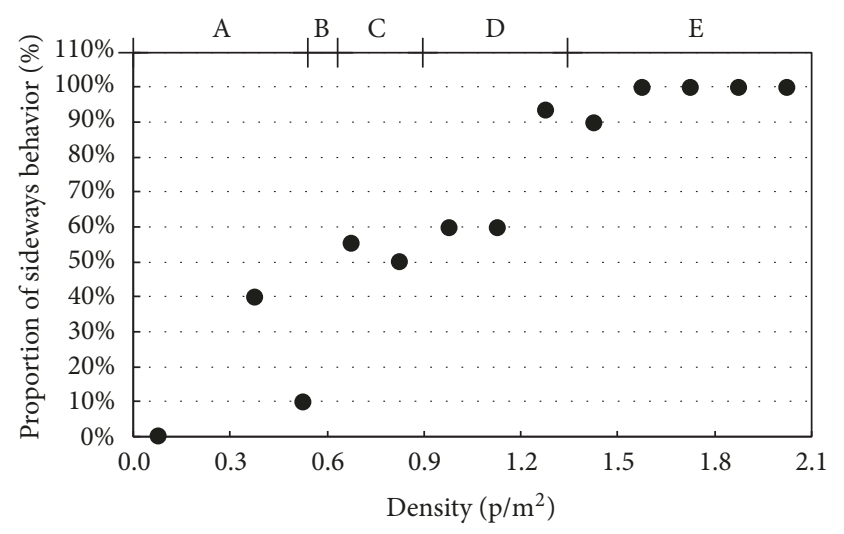

FIGURE 13: Proportion of sideways pedestrian evasive behavior with the increase of density.

$$
\begin{aligned}
\rho_{\mathrm{e}}= & -0.7964 \times \mathrm{D}^{3}+6.6796 \times \mathrm{D}^{2}-18.654 \times \mathrm{D} \\
& +17.519 \\
\mathrm{R}^{2}= & 0.9094
\end{aligned}
$$

where $\mathrm{D}$ means the pedestrian flow density and $\rho_{\mathrm{e}}$ is the occurrence intensity of pedestrian evasive behavior.

4.2. Proportion of Sideways Pedestrian Evasive Behavior. To show the difficulty of pedestrian evasive behavior at different densities, almost $70 \%$ of evasive behaviors are sideways behaviors. Figure 13 illustrates the proportion of sideways evasive behavior at the different LOS. The proportion of sideways behavior shows an increasing trend from LOS A to LOS D. The evasive behavior events are totally the sideways behaviors when the density is larger than $1.5 \mathrm{p} / \mathrm{m}^{2}$ at LOS E. Compared with the characteristics of proportion of sideways overtaking behavior, evasive behavior needs more space to take behavior, which will be discussed in Section 4.3. 


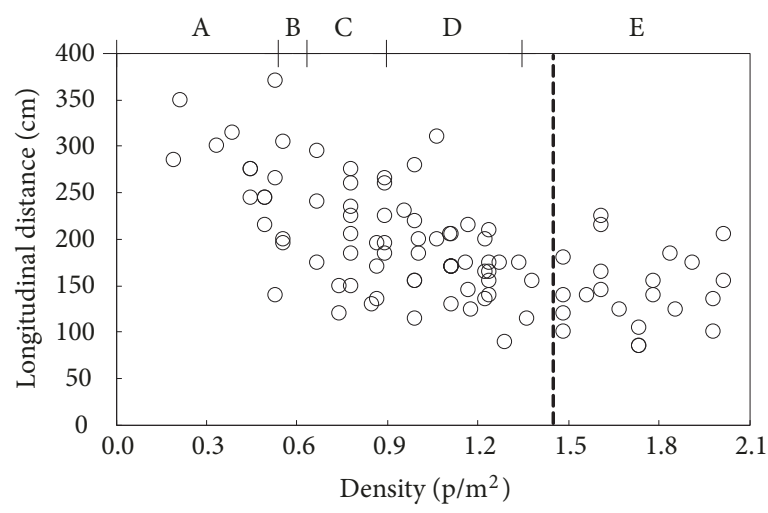

(a) Longitudinal distance indicator

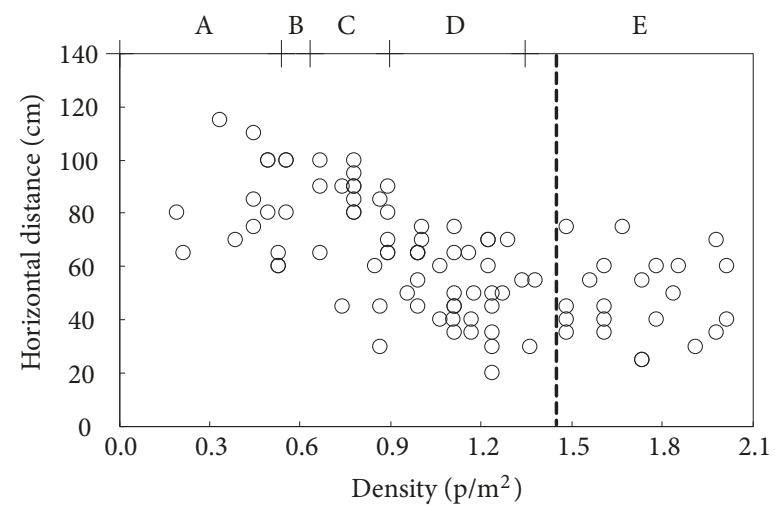

(b) Horizontal distance indicator

FIGURE 14: Microscopic distance indicators of pedestrian evasive behavior.

TABLE 4: Description of distance indicators on bidirectional stairways.

\begin{tabular}{lcc}
\hline Descriptive indexes & $\mathrm{L}_{\mathrm{e}}$ & $\mathrm{H}_{\mathrm{e}}$ \\
\hline Sample size & 96 & 96 \\
Min $(\mathrm{cm})$ & 85 & 20 \\
Mean $(\mathrm{cm})$ & 188.4 & 61.2 \\
Max $(\mathrm{cm})$ & 370 & 115 \\
Key density $\left(\mathrm{p} / \mathrm{m}^{2}\right)$ & 1.45 & 1.45 \\
Average value $(\mathrm{cm})$ & 144.2 & 46.4 \\
Range of density $\left(\mathrm{p} / \mathrm{m}^{2}\right)$ & $0.19-2.22$ & $0.19-2.22$ \\
\hline
\end{tabular}

4.3. Microscopic Characteristics of Distance Indicators. To analyze the microscopic characteristics of distance indicators, 96 samples of the pedestrian evasive behavior events on bidirectional stairway are selected. The description of such indicators including the initial longitudinal distance $\left(\mathrm{L}_{\mathrm{e}}\right)$ and the final horizontal distance $\left(\mathrm{H}_{\mathrm{e}}\right)$ is shown in Table 4 . Figure 14 shows the relationship between these two distance indicators and density.

As can be seen in Figure 14, both $\mathrm{L}_{e}$ and $\mathrm{H}_{\mathrm{e}}$ show a decreasing trend when the density increases from $0.19 \mathrm{p} / \mathrm{m}^{2}$ to $1.45 \mathrm{p} / \mathrm{m}^{2}$, as well as the LOS A, B, C, and D. This finding indicates that the increasing density leads to the reduction of available longitudinal and horizontal space, and the total space for taking evasive behaviors becomes smaller and smaller. Therefore, the ability of taking evasive behaviors is restricted severely.

When the density is larger than $1.45 \mathrm{p} / \mathrm{m}^{2}$, there is no significant relationship between $\mathrm{L}_{\mathrm{e}}$ or $\mathrm{H}_{\mathrm{e}}$ and density at LOS E. The average value of $\mathrm{L}_{\mathrm{e}}$ is about $145 \mathrm{~cm}$ when density is larger than $1.45 \mathrm{p} / \mathrm{m}^{2}$, almost two times compared with the average value of $\mathrm{L}_{\mathrm{o}}$ with the density larger than $1.05 \mathrm{p} / \mathrm{m}^{2}$, while the value of $\mathrm{H}_{e}$ is about $45 \mathrm{~cm}$.

The microscopic characteristics also support the occurrence intensity features, of which first remains stable and then decreases. At low density, the increase of density leads to much interaction among pedestrians and much demand for taking evasive behaviors, but the available space reduces synchronously. Therefore, the occurrence intensity maintains a stable level due to the trade-off between demand and space supply. As the density increases further, the interference among pedestrians intensifies continuously, while the space supply becomes decreasing, resulting in the rapid decrease of occurrence intensity. Finally, the basic space requirement for evasive behavior is not large enough, leading to none of pedestrian evasive behavior events. In this case, pedestrians walk forward by following the lanes of their own directions.

Compared with the results of two such behaviors, we find that there are similarities and differences between pedestrian overtaking behavior and pedestrian evasive behavior in terms of the macro and micro characteristics. As for similarities, neither the overtaking behavior events nor the evasive behavior events can be observed at extremely lowor high-density level. Meanwhile, when the density increases from the extremely low level, the occurrence intensity of overtaking behavior increases rapidly, but that of evasive behaviors remains relatively stable. This is mainly due to the different change rules of space supply for different PIBs with the continuous increase of density. Meanwhile, it may also be attributed to the different natures of the two types of behavior. If the space allows, all individual pedestrians have probability to overtake others, while pedestrian evasive behavior mainly occurs at the interface of two flows in different directions. As for the distance indicators, the average value of $\mathrm{L}_{\mathrm{e}}(188 \mathrm{~cm})$ shows two times larger than the value of $\mathrm{L}_{\mathrm{o}}(90 \mathrm{~cm})$ due to the more space demand of pedestrian evasive behavior. The value of $\mathrm{H}_{\mathrm{e}}(60 \mathrm{~cm})$ is similar to the value of $\mathrm{H}_{\mathrm{o}}(65 \mathrm{~cm})$ because of the width demand of a person walking alone.

\section{Discussions}

Based on the macro and micro characteristics of PIBs on stairways, Table 5 shows the critical densities with the descriptions found in our research. For example, when the density is less than $0.15 \mathrm{p} / \mathrm{m}^{2}$ or the space is larger than 71.8 $\mathrm{ft}^{2} / \mathrm{p}$, none of PIBs could be observed. For LOS B, the largest intensity of pedestrian overtaking behavior on descending stairway is observed with the density of $0.65 \mathrm{p} / \mathrm{m}^{2}$. The horizontal distance of overtaking behavior on descending 
TABLE 5: Critical densities observed in this study.

\begin{tabular}{lcc}
\hline Density $\left(\mathrm{p} / \mathrm{m}^{2}\right.$ and $\left.\mathrm{ft}^{2} / \mathrm{p}\right)$ & LOS based on HCM & Description of the critical density \\
\hline $0.15(71.8)$ & $\mathrm{A}$ & None of PIBs \\
$0.225(47.8)$ & $\mathrm{A}$ & Pedestrian overtaking behavior events could be observed \\
$0.65(16.6)$ & $\mathrm{B}$ & The largest intensity of overtaking behavior on descending stairway \\
$0.75(14.3)$ & $\mathrm{C}$ & Key density of horizontal distance on descending stairway \\
$0.975(11.0)$ & $\mathrm{D}$ & The largest intensity of overtaking behavior on ascending stairway \\
$1.05(10.2)$ & $\mathrm{D}$ & Key density of longitudinal distance for overtaking behavior \\
$1.45(7.4)$ & $\mathrm{E}$ & Key density of longitudinal distance for evasive behavior \\
$1.6(6.7)$ & $\mathrm{E}$ & All the overtaking behavior events are the sideways behaviors \\
$1.875(5.7)$ & $\mathrm{E}$ & None of pedestrian overtaking behavior on descending stairway \\
$2.325(4.6)$ & $\mathrm{F}$ & None of pedestrian overtaking behavior on ascending stairway \\
$3.15(3.4)$ & $\mathrm{F}$ & None of pedestrian evasive behavior \\
\hline
\end{tabular}

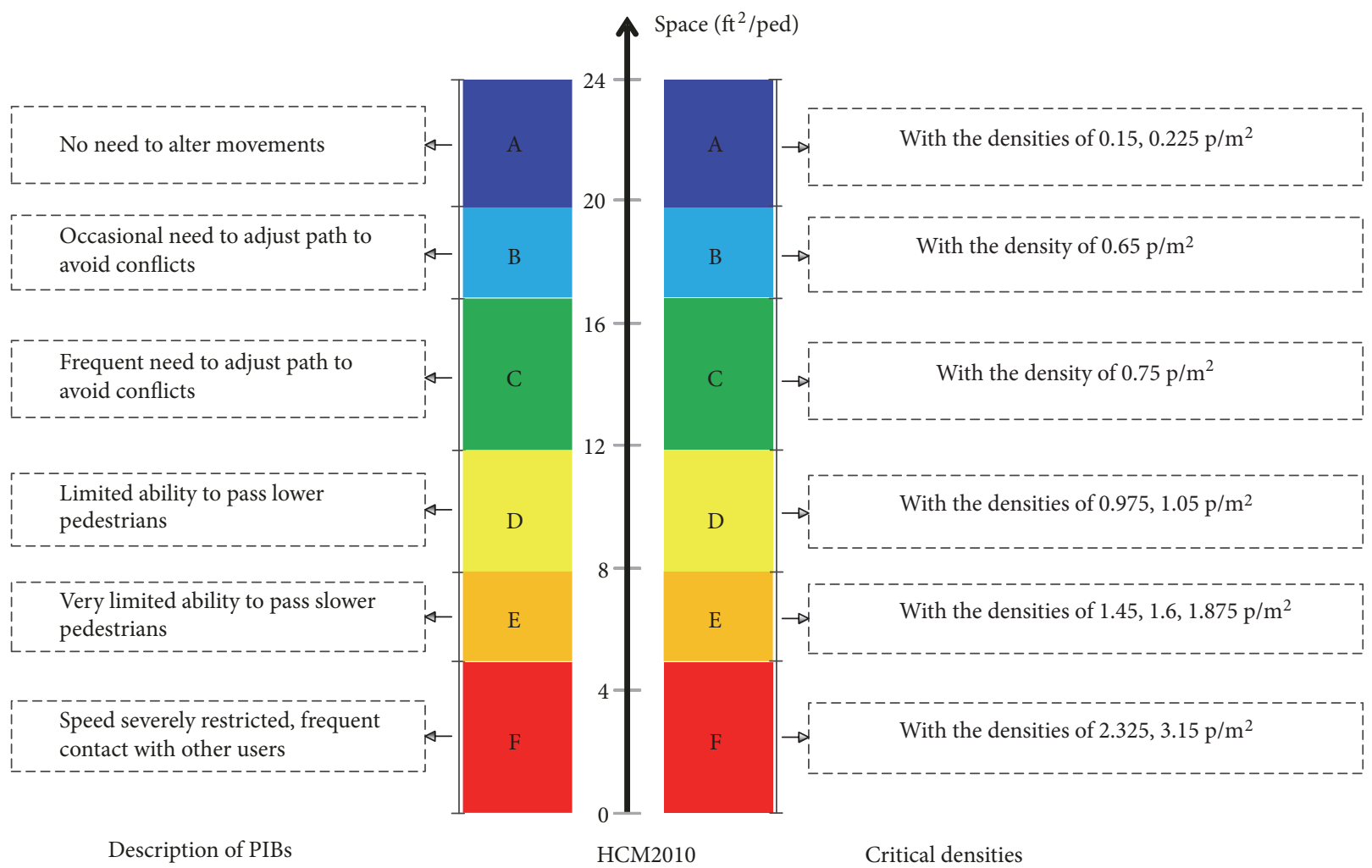

FIgURE 15: Descriptions of PIBs in HCM 2010 and critical densities identified in this study.

stairway becomes decreasing when the density is larger than $0.75 \mathrm{p} / \mathrm{m}^{2}$ at LOS C. Meanwhile, the longitudinal distance for overtaking behavior keeps a stable value, when the density is larger than $1.05 \mathrm{p} / \mathrm{m}^{2}$ at LOS D. All the PIB events are the sideways behaviors at LOS E. None of pedestrian evasive behaviors could be observed when the density is larger than $3.15 \mathrm{p} / \mathrm{m}^{2}$ at LOS F.

The left part of Figure 15 shows the description of PIBs presented in HCM 2010, while the right part of Figure 15 shows the critical densities identified in this study. There are some differences between the two different descriptions, compared with the description of the critical density presented in Table 5 and the description presented in the left part of Figure 15. For example, the largest intensity of overtaking behavior on ascending stairway is at LOS D, while the description of HCM 2010 is "limited ability to pass lower pedestrians." And none of pedestrian overtaking behaviors on descending stairway could be found in LOS E, while the description of LOS E is very limited ability to pass slower pedestrians. It is reasonable for such differences due to the differences of the observation environment and the different walking directions. 


\section{Conclusions}

Pedestrian interactive behaviors, such as overtaking behavior and evasive behavior, are crucial elements for better understanding pedestrian flow on stairways. This paper aims to explore the characteristics of PIBs under the different LOS on stairways. Related indicators are proposed and calculated based on field observation, including occurrence intensity, proportion of sideways behavior, longitudinal distance, and horizontal distance. Then, pedestrian overtaking behavior and evasive behavior features are analyzed, with the consideration of different pedestrian flow densities. The relationship between macro indicators and micro indicators are discussed. Lastly, the description of PIBs on stairways presented in HCM 2010 is discussed and revised based on the characteristics of PIBs.

Results show that the occurrence intensities of PIBs first increase and then show a decreasing trend with the increasing density. Neither of the two types of behavior occurs at extremely low or high density. At extremely low density, pedestrians walk individually with no need to take PIBs. At extremely high density, there is no enough available space for taking overtaking behavior or evasive behaviors, resulting in none of PIBs. At the other ranges of density, the occurrence intensity of interactive behavior presented the tendency of first increasing and then decreasing. This is mainly due to the change of available space for PIBs with the increase of density. As for sideways behavior, the proportion of sideways behavior shows a rapid increasing trend from LOS A to LOS D. At LOS E, all the observed PIB events are sideways behaviors.

The longitudinal distance indicator of pedestrian overtaking behavior first shows a decreasing trend and then keeps a stable value with the key density of $1.05 \mathrm{p} / \mathrm{m}^{2}$, while the horizontal distance indicator first shows no significant relationship with density and then decreases with the continuous increase of density. As for pedestrian evasive behavior, the micro distance indicators first decrease and then keep a certain value with the increase of density. The key density is $1.45 \mathrm{p} / \mathrm{m}^{2}$.

Based on the findings of our research, there are some differences compared with the descriptions presented in HCM 2010 and the descriptions of critical densities identified in this study. The findings of our research are helpful to understand the knowledge of pedestrian behavior on stairways for a better stairway traffic design and level of service evaluation.

One of the limitations of this study is that only the second flight of the ascending stairway and the top flight of the descending stairway are selected as the observed objects. More field observations should be conducted to analyze the characteristics of PIBs on stairways. Meanwhile, more researches should be done to propose a local level of service criteria of pedestrian stairways. And other factors such as gender, age, walking speed, and luggage-carrying also need to investigate their impacts on the PIBs. In addition, comparative analysis between level passageway and stairway is also helpful to comprehensively grasp the characteristics of PIBs on stairways.

\section{Data Availability}

The data used to support the findings of this study are included within the supplementary information file.

\section{Disclosure}

The contents of this paper reflect the views of the authors who are responsible for the facts and the accuracy of the data presented herein. The contents do not necessarily reflect the official views. This paper does not constitute a standard, specification, or regulation. The manuscript is based on a Poster Paper that was presented at Transportation Research Board 94th Annual Meeting “https://trid.trb.org/view/1336821”.

\section{Conflicts of Interest}

The authors declare that they have no conflicts of interest.

\section{Acknowledgments}

This research is supported by the Fundamental Research Funds for the Central Universities (no. 2018B08014) and by the National Natural Science Foundation of China (no. 51108342). The authors also acknowledge Shanghai Shentong Metro Co., Ltd. for the aid in data collection.

\section{Supplementary Materials}

Data of macro and micro characteristics of pedestrian overtaking behavior and evasive behavior have been supplied. (Supplementary Materials)

\section{References}

[1] J. Templer, The staircase: Studies of Hazards, Falls, and Safer Design, Mit Press, 1995.

[2] M.-H. Yi, W.-J. Na, W.-H. Hong, and G.-Y. Jeon, "Pedestrian walking characteristics at stairs according to width change for application of piezoelectric energy harvesting," Journal of Central South University of Technology, vol. 19, no. 3, pp. 764769, 2012.

[3] L. Yang, P. Rao, K. Zhu, S. Liu, and X. Zhan, "Observation study of pedestrian flow on staircases with different dimensions under normal and emergency conditions," Safety Science, vol. 50, no. 5, pp. 1173-1179, 2012.

[4] T. Fujiyama and N. Tyler, "Predicting the walking speed of pedestrians on stairs," Transportation Planning and Technology, vol. 33, no. 2, pp. 177-202, 2010.

[5] T. Fujiyama and N. Tyler, "An Explicit Study on Walking Speeds of Pedestrians on Stairs," 2004.

[6] X. Zhao, Y. Wu, G. Ren, K. Ji, and W. Qian, "Clustering analysis on ridership patterns at subway stations: a case in Nanjing, China," Journal of Urban Planning and Development, vol. 145, no. 2, Article ID 04019005, 2019.

[7] M. Wolff, "Notes on the behavior of pedestrians," in People in Places: the Sociology of the Familiar, A. Birenbaum, Ed., pp. 3548, Nelson, London, UK, 1973.

[8] K. Tatebe and H. Nakajima, "Avoidance behavior against a stationary obstacle under single walking," Journal of Architecture and Planning (Transactions of AIJ), vol. 418, pp. 51-57, 1990. 
[9] K. Miyazaki, H. Mastukura, M. Katuhara et al., "Behaviors of pedestrian group overtaking wheelchair users," in Pedestrian and Evacuation Dynamics, pp. 267-278, CMS Press, London, UK, 2003.

[10] B. Pushkarev and J. M. Zupan, Urban Space for Pedestrian, The MIT Press, 1975.

[11] X. Shan, J. Ye, and X. Chen, "Proposing a revised pedestrian walkway level of service based on characteristics of pedestrian interactive behaviors in China," Promet Traffic \& Transportation, vol. 28, no. 6, pp. 583-591, 2016.

[12] K. Kitazawa and T. Fujiyama, "Pedestrian vision and collision avoidance behavior: investigation of the information process space of pedestrians using an eye tracker," in Pedestrian and Evacuation Dynamics, pp. 95-108, 2008.

[13] S. Kim, J. Choi, S. Kim, and R. Tay, "Personal space, evasive movement and pedestrian level of service," Journal of Advanced Transportation, vol. 48, no. 6, pp. 673-684, 2014.

[14] J. Wu, J. Feng, and S. Lu, "Research on pedestrian overtaking behavior in passageway," Journal of Tongji University, vol. 40, no. 2, pp. 228-234, 2012.

[15] J. Pauls, "Demographic changes leading to deterioration of pedestrian capabilities affecting safety and crowd movement," in Proceedings of the Transportation Research Board 87th Annual Meeting, 2008.

[16] T. Fujiyama and N. Tyler, "Bidirectional collision-avoidance behaviour of pedestrians on stairs," Environment and Planning B: Planning and Design, vol. 26, no. 1, pp. 128-148, 2009.

[17] Transportation Research Board, "Highway Capacity Manual 2010," Washington DC, USA, 2010.

[18] J. Fruin, Pedestrian Planning and Design, Metropolitan Association of Urban Designers and Environmental Planners, New York, NY, USA, 1971. 


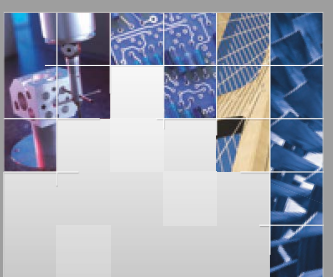

\section{Enfincering}
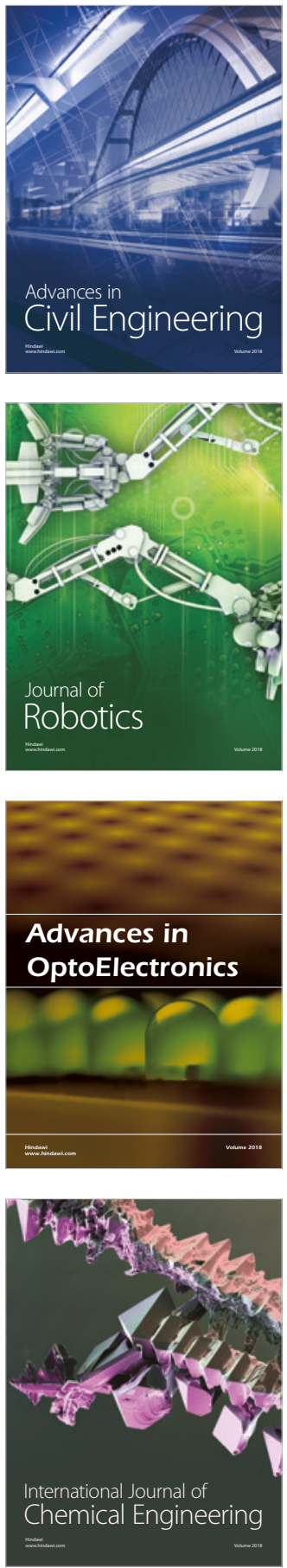

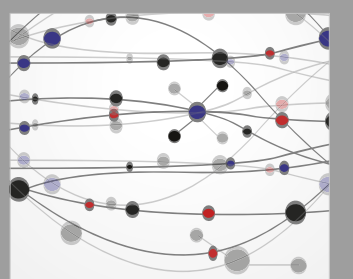

\section{Rotating \\ Machinery}

The Scientific World Journal

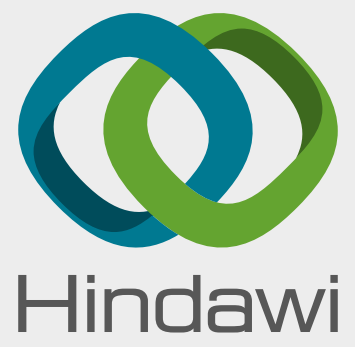

Submit your manuscripts at

www.hindawi.com
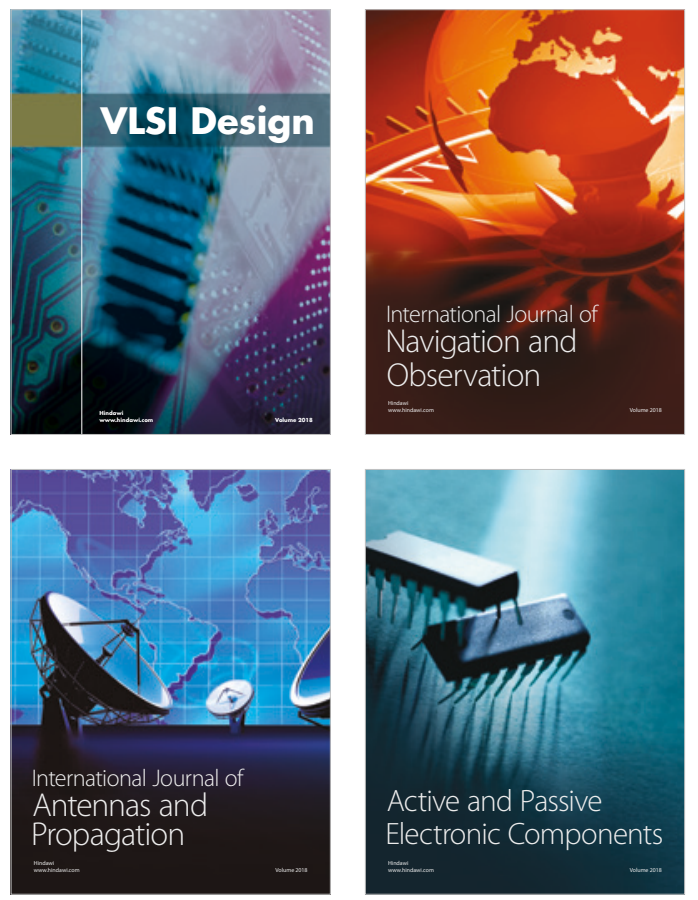
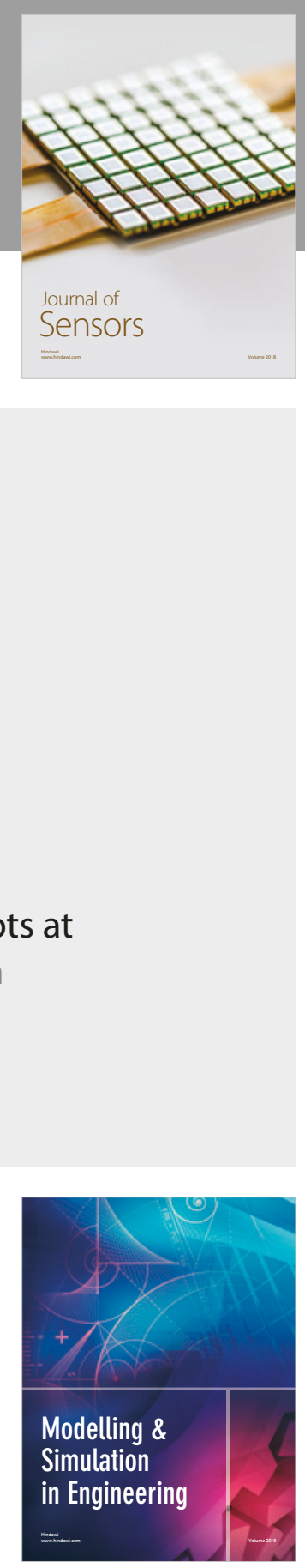

\section{Advances \\ Multimedia}
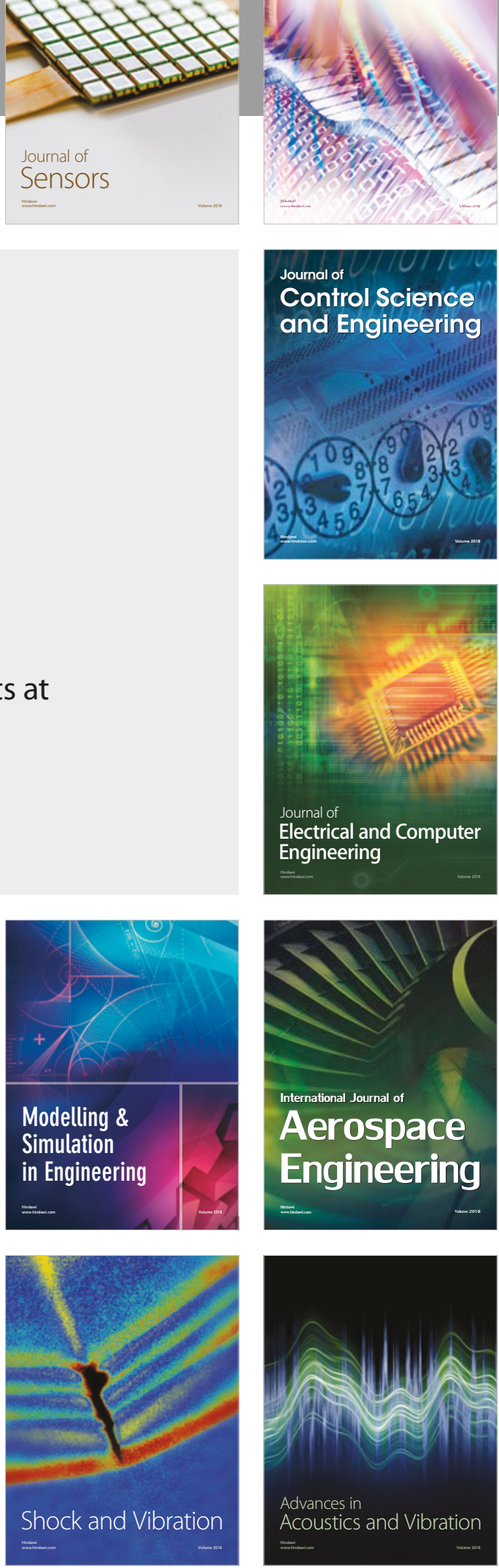